S1

\title{
Extension of the experimental electron density analysis to metastable states: a case example of the spin crossover complex $\mathrm{Fe}(\mathrm{btr})_{2}(\mathrm{NCS})_{2} \cdot \mathrm{H}_{2} \mathrm{O}$
}

Vincent Legrand, Sébastien Pillet, Mohamed Souhassou, Noël Lugan, and Claude Lecomte SUPPORTING INFORMATION 

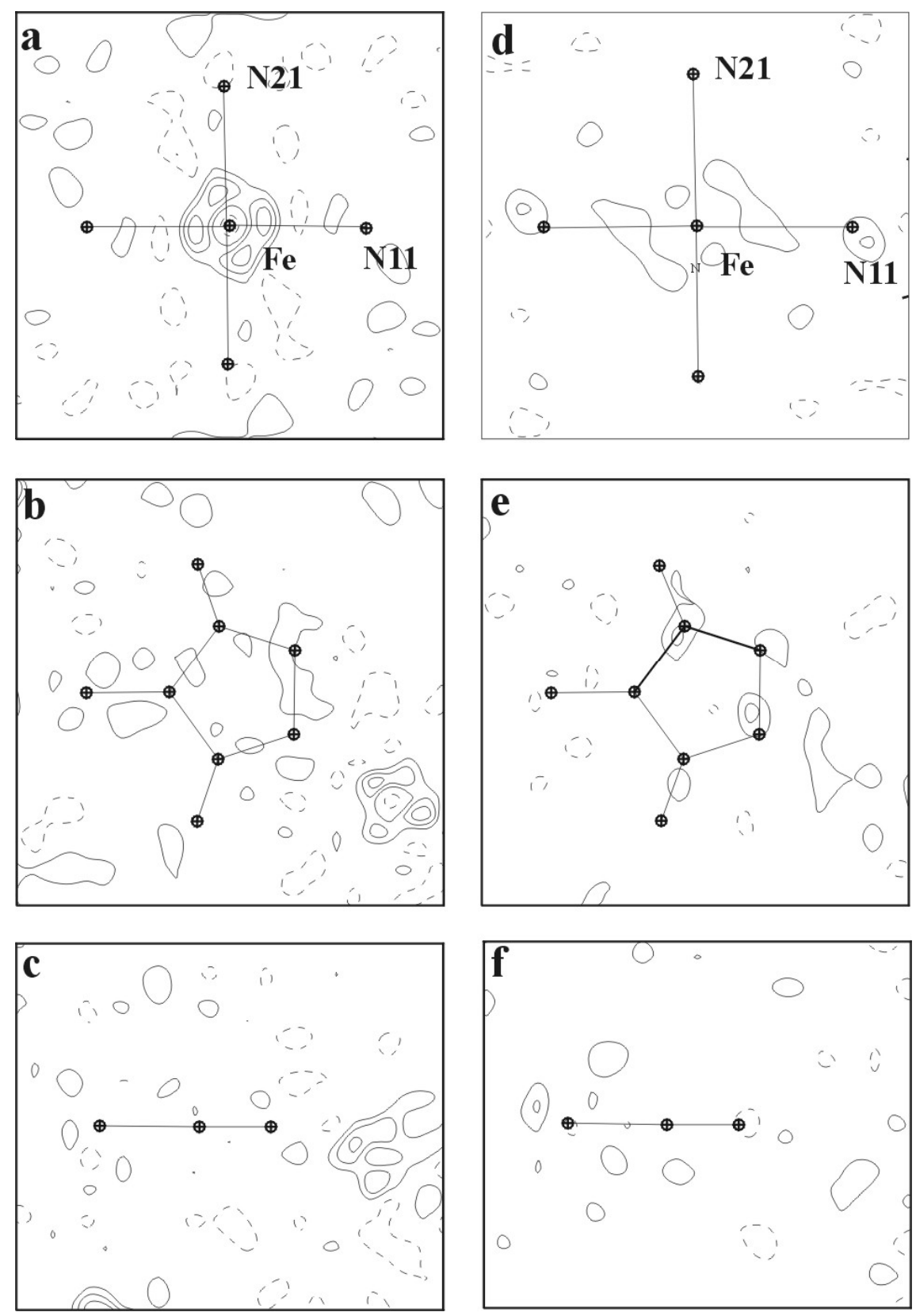

Figure 1. Residual electron density in the Fe-N11-N21, triazole ring and NCS plane for the HS (left) and LS (right) states. Contour levels : $0.1 \mathrm{e}^{-3}$ positive solid lines and negative dashed. 

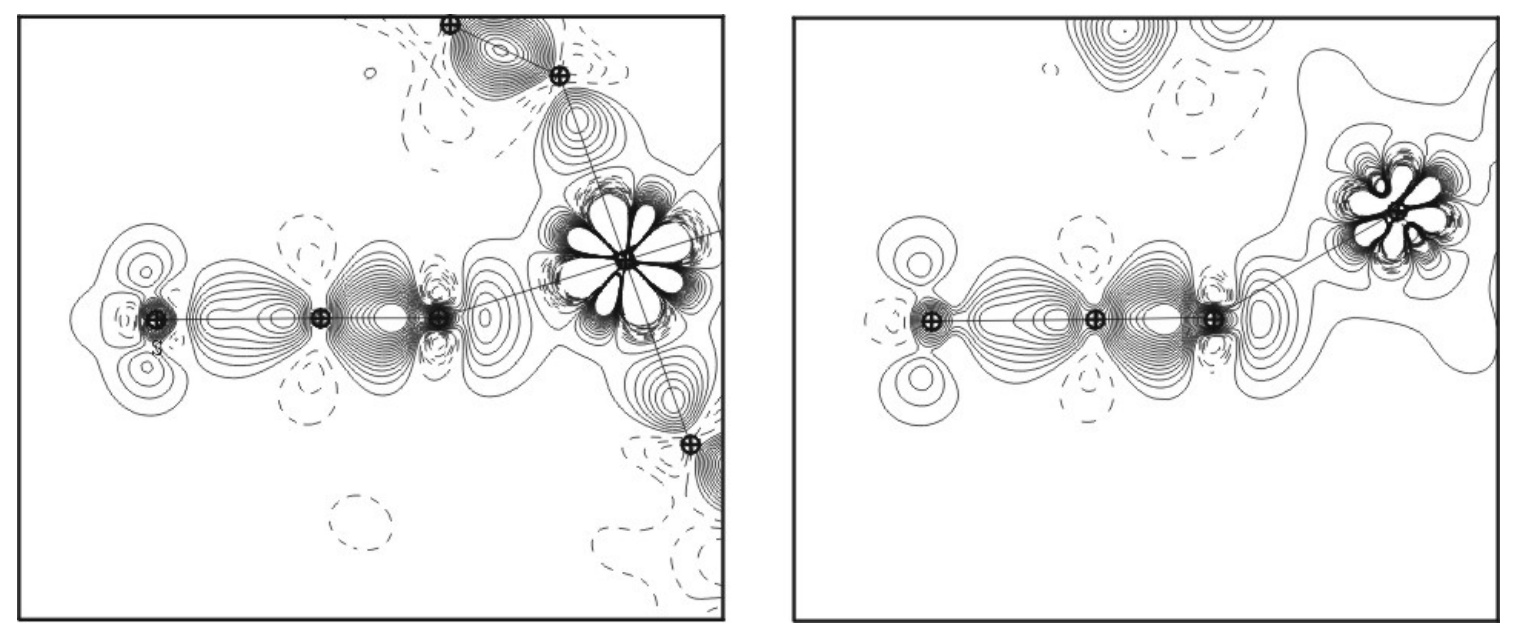

Figure 2. Static deformation density in the NCS plane for the LS (left) and HS (right) states. Contour levels : $0.05 \mathrm{e}^{-3}$ positive solid lines and negative dashed. 


\section{S4}

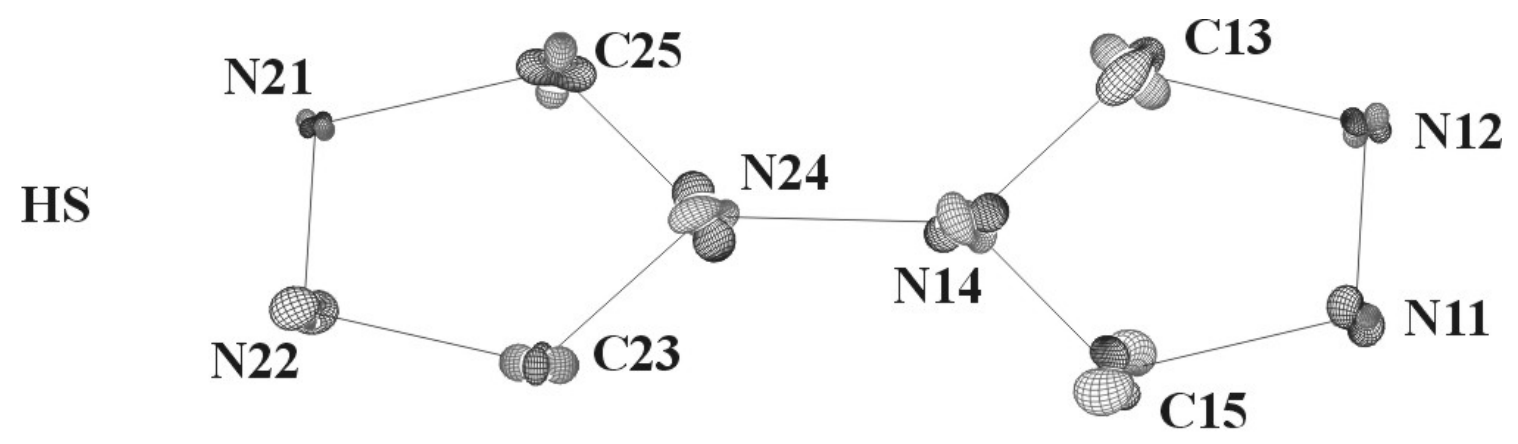

LS

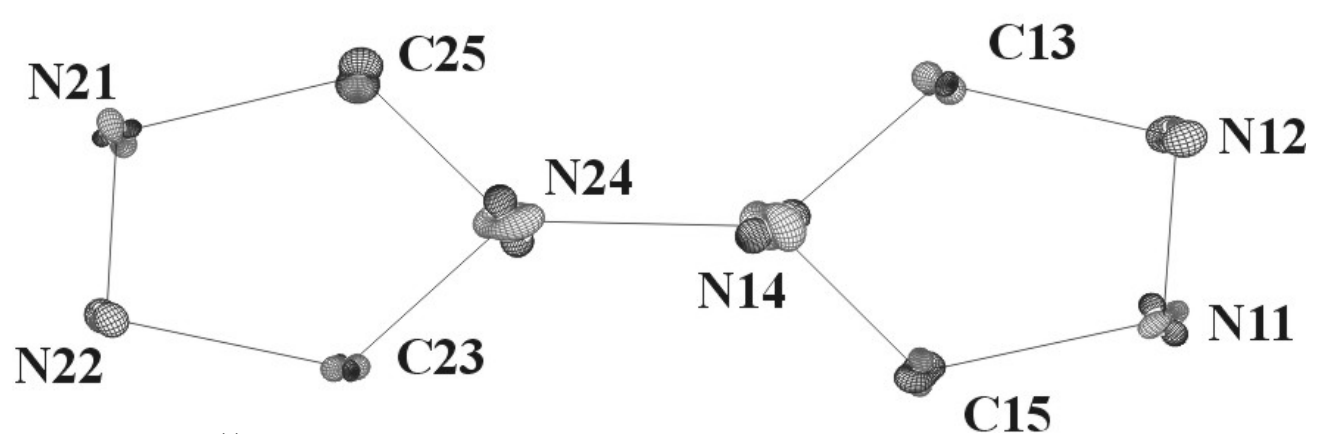

Figure 3. PEANUT plot ${ }^{44}$ showing the RMS surfaces of the difference between the observed (refined) and rigid body (TLS model) atomic displacement parameters at the $100 \%$ probability level for the HS and LS states. Positive surface in grey, negative in black. 